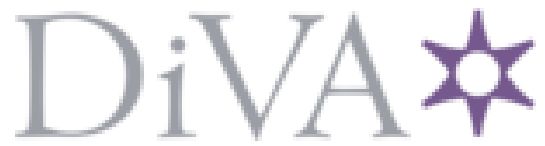

http://www.diva-portal.org

Postprint

This is the accepted version of a paper presented at 2017 International Conference on Military Technologies (ICMT) May 31 - June 2, 2017, Brno, Czech Republic.

Citation for the original published paper:

Andersson, K. (2017)

An Exploratory Case Study on Swedish Development of Low Observable Vehicles In: Krivanek, V. (ed.), Proceedings of the 2017 International Conference on Military Technologies (ICMT) (pp. 123-129). Brno

https://doi.org/10.1109/MILTECHS.2017.7988743

N.B. When citing this work, cite the original published paper.

Permanent link to this version:

http://urn.kb.se/resolve?urn=urn:nbn:se:fhs:diva-6724 


\title{
An Exploratory Case Study on Swedish Development of Low Observable Vehicles
}

\author{
Kent Andersson \\ Swedish Defence University, and National Defence University of Finland, \\ Box 278 05, 11593 Stockholm, Sweden, e-mail: kent.andersson@fhs.se
}

\begin{abstract}
A case study approach, based on interviews and document reviews, was used to analyze the systems engineering processes of the SEP (Armored Multirole Vehicle, in Swedish) and the Visby class corvette cases respectively. The focus was on signature management. The result is a thorough investigation of what worked in the cases studied. The main conclusions can be summarized in three points. 1) A preferred workflow from mission analysis to sub system design has been derived from lessons identified; 2) The three main success factors identified were: building technology demonstrators, having an Integrated Product Team approach, and establishing stealth as a key system design goal; 3) Coherence and traceability between military needs on the battlefield and signature requirements need further research.
\end{abstract}

Keywords-component; Low Observable Technology, Stealth, Signature, Survivability, Systems Engineering, SEP, Visby class corvette

\section{INTRODUCTION}

Until the end of the Cold War, Swedish doctrine was focused on national defense. Significant expertise and experience in signature management for combat vehicles was gathered in development projects like the S-tank and the CV90, and also in tests and trials when procuring the Leopard main battle tank ${ }^{1}$. Here signature is understood to be any characteristic making an object detectable with a sensor. In 1985 an R\&D program started with the aim of studying how Low Observable Technology (LOT), i.e. for reducing signature, could be applied to the next generation of surface ships for the Royal Swedish Navy (RSwN). The program resulted in a test vessel called Smyge, which was in operation until 1995. The Smyge test program not only spurred the use of stealth in what became the Visby class corvette, but also inspired a joint service R\&D demonstrator program for stealth on land in 1996 called SAT/Mark. In parallel with the launch of the SAT/Mark (LOT/Land, in Swedish) program, a study of replacement combat vehicles for Swedish land forces recommended developing an Multirole Armored Platform concept (SEP, in Swedish). Multispectral signature adaptation, particularly in the infrared (IR) and radar domains, was identified among the technologies of special interest to support the concept [1].

The SAT/Mark project also resulted in the publication of results relating to the development of stealthy land combat

${ }^{1}$ Rickard O. Lindström, strategic specialist in combat vehicles at the Swedish Defence Materiel Administration, FMV, interview, 25th of March 2015 vehicles [2,3]. However, in the last decade there have been very few reports of new research into the issue. The survivability focus of the reports found seem to be on vulnerability or active protection (e.g. $[4,5,6]$ ), and none of them provide any new guidance on the signature engineering process or on signature requirements management.

Since signature management is of increasing importance in enhancing the survivability of land forces in future conflicts, it is important not to lose sight of lessons identified a decade ago. The question in focus is hence how to achieve favorable conditions for the design of the next Low Observable military vehicle. Therefore, the scope of the first part of the study, reported in this paper, is to collect possible lessons identified from earlier development of balanced stealth designs. The final step will be to analyze these in relation to a presumed European capability development environment of the near future. The focus is on land vehicles, which is why the SEP development process is the primary case studied. The Visby class corvette case is mainly used for comparison in order to support generalization of results.

Next, in the theory section of the paper, the survivability engineering discipline within Systems Engineering (SE), is presented. Thereafter, the research approach, including the case study method and the sources, is described, followed by a short description of the two cases. In the subsequent analysis section, results of the analysis are presented. Finally, the results are discussed and conclusions are presented.

\section{SYSTEMS ENGINEERING}

This study takes an SE perspective on signature management. SE is recognized among most western states and major defense industries as the preferred way of acquiring complex military products. It can be described as an iterative process, involving both technical and management components, with the goal of providing a quality product that meets user needs [7]. Best practice SE involves coordinating all specialist engineering activities, including survivability engineering.

Survivability of a platform is enhanced either by reducing its vulnerability or its susceptibility to hostile actions [8]. LOT is used to reduce the passive signature of a platform, thereby also reducing the probability of detection. Thus, it is one way to reduce susceptibility. In this paper survivability engineering activities aimed at meeting signature requirements during development are also referred to as signature engineering. 
So far survivability engineering, including signature engineering, has mostly been studied in relation to combat aircraft design. The main challenge originates from the interdependence of the attributes of a platform. The combat aircraft community stresses that the goal of survivability engineering is to increase the cost effectiveness of the weapons system, not to design the most survivable platform possible [8]. The shaping necessary to reduce radar signature will for example also reduce maneuverability and payload. It is therefore necessary to find a balance in the corresponding system requirements on the design. According to Ball the most important success factors are [8: p. 44-50, 174]:

- To measure system effectiveness of a combat aircraft in terms of offensive capability, availability and survivability,

- To evaluate the design of a platform as a component in a mission system,

- For the design team to consider survivability at an early stage, because retrofitting survivability features usually adds unnecessary penalties to the design, e.g. weight or cost, and

- For survivability engineers to work continuously in close cooperation with designers, the program manager and operators, and that they should be allowed real influence.

Typically, the main SE effort occurs early in a systems life cycle, i.e. in the concept or development life-cycle stages. The rationale is that already after design some $85 \%$ of the total life cycle cost of a complex product is committed [7]. A design is a solution description resulting from the development life-cycle stage. It is based on system requirements derived from the stakeholder needs and the conceptual solution identified in the concept stage, and it is limited by the competence of and the technology available to the development organization [7]. Hence, this study is focused on the search for lessons in the concept and development life-cycle stages and on those SE processes that support the derivation of system requirements and system design.

\section{RESEARCH APPROACH}

\section{A. Data collection and sources}

Data was collected using an exploratory case study method [9]. The two cases studied, development of the SEP combat vehicle and the Visby class corvette respectively, were chosen because of the prominent role signature management played in the systems architecture of each platform. In this respect these projects are currently unique to Sweden, and are two of but a few comparable land or maritime projects worldwide. In addition, because of their uniqueness, these two programs were also the only relevant options where data was available to the author.

The focus of this paper is on land combat vehicles; a comparison between the SEP case and the Visby case is used to support validation of results.

Data in the SEP case was collected using interviews of key personnel from government organizations and contractors, and from a review of relevant documents. The respondents were selected on the basis of having played key roles during development. In the Visby case two respondents were interviewed, who at the time filled roles as signature coordinators in the government project. Table I presents the roles of the respondents in the respective cases.

TABLE I. ROLES OF THE RESPONDENTS

\begin{tabular}{|c|c|c|}
\hline Respondent & SEP program & Visby program \\
\hline A & $\begin{array}{c}\text { Head of plans and policies } \\
\text { in SwAF }{ }^{\mathrm{a}} \mathrm{HQ}\end{array}$ & \\
\hline B & $\begin{array}{l}\text { SwAF Project Manager } \\
(\mathrm{PM}) \text { for SEP program }\end{array}$ & \\
\hline $\mathrm{C}$ & $\begin{array}{l}\mathrm{FMV}^{\mathrm{b}} \mathrm{PM} \text { for SAT/Mark } \\
\text { demonstrator }\end{array}$ & \\
\hline $\mathrm{D}$ & FMV PM for SEP program & \\
\hline $\mathrm{E}$ & $\begin{array}{l}\text { FOI }^{\mathrm{c}} \text { Senior scientist threat } \\
\text { assmnt and signature reqs }\end{array}$ & \\
\hline $\mathrm{F}$ & $\begin{array}{l}\text { Contractor PM for SEP, } \\
\text { and signature specialist }\end{array}$ & \\
\hline G & $\begin{array}{c}\text { Contractor signature } \\
\text { specialist for SAT/Mark }\end{array}$ & \\
\hline $\mathrm{H}$ & & $\begin{array}{l}\text { SwAF product mgr for } \\
\text { Smyge demonstrator and } \\
\text { FMV Signature coord. } \\
\text { for Visby prgm 1995-99 }\end{array}$ \\
\hline I & & $\begin{array}{l}\text { FMV Signature coord. } \\
\text { for Visby prgm } 2000-01\end{array}$ \\
\hline
\end{tabular}

The basic structure of the interviews was to ask respondents to describe, from their perspective, each step of the development process, and to ask, given their experiences, what could be learned for future projects. The questions were structured following the technical processes in best practice SE [7].

Document reviews were used, when such documents were available, to support key statements from the respondents. There are reports from the Swedish Defence Research Agency (FOI) from the early stages of the SAT/Mark program, in 1998, concerning modeling issues and requirements specification [10, 11 ], and a handbook on signature management for ground vehicles [12]. The handbook provides lessons learned in the form of engineering guidelines for the construction and evaluation of low observable vehicles. The experiences of both the Swedish procurement agency (FMV) and industry from the development of the SAT/Mark demonstrator also resulted in conference papers presented to SPIE [2, 3]. A lessons-learned report to the Swedish Armed Forces (SwAF) by the SEP project management is partly unclassified and useful for reviewing the schedule and key management events [13]. Symposium proceedings from presentations given after the launch of the Visby corvette in June 2000 have been used for background information and for general lessons learned in the Visby case [14]. Project documentation concerning numeric measures for system signature requirements and verified results are, however, confidential. Nevertheless, it has been possible to discuss results on a general level with the respondents. This has proven sufficient for drawing conclusions on methods and procedures. 


\section{B. Analysis approach}

The aim of the analysis was to identify lessons from the development processes of the two cases, using a framework [15] of concepts for best practice systems engineering as a filter. The framework was chosen because it was developed for, and has been used as, the baseline assessment tool in similar evaluations $[15,16,17]$. Because the focus was on the $\mathrm{SE}$ technical processes covering requirements analysis, systems architecture and design, the following subset of SE-concepts [15] were used:

1) Requirements management

- "A1. Requirements shall flow down in a coherent and traceable manner from the top level to all lower levels of the system being engineered."

- "A2. Customer and contractor shall share with one another their knowledge of the state of technical maturity relative to the new, unprecedented systems being engineered."

- "A3. The government shall integrate the needs of its user organizations with the management activities of its developmental organizations."

2) Systems Architecture

- "B1. The systems baseline architecture of complex programs shall be established early in every program and shall involve all dimensions of technical issues, as well as such enterprise architecture issues as customer needs and satisfaction, political pressures and continuity of funding. A properly executed systems architecture activity provides benefits of effectiveness far in excess of its costs."

- "B2. The systems architecture should be established early for the reasons stated in B1, and the best judgment of both government and contractor shall be employed across all the key issues, including the choice of employing newly developed or legacy systems."

3) System and Subsystem design

- "C1. System design shall proceed in a logical and orderly manner through a process of functional decomposition and design traceability that originates with the system functional architecture and ultimately results in design specifications for the system to be engineered."

4) System and program management

- "I2. The role of systems engineering in program development and management shall be recognized and supported."

\section{CASE DESCRIPTIONS}

An overview of the major events and decisions shaping the early stages of the SEP and the Visby lifecycles is presented. Note that the SEP and the Visby development programs were each preceded by R\&D Low Observable technology demonstrator projects: the SAT/Mark and Smyge projects respectively. Subsequently, and in this study, these projects can be viewed as knowledge building activities in the respective concept stages, not least in terms of the transfer of knowledge of low observable technology from long-term defense research $[2,18]$.

\section{A. The SAT/Mark and SEP programs}

In 1993 SwAF identified a need to replace about 7000 tracked combat vehicles in the Swedish Army during a period stretching from 2005 to 2015. A SwAF study was initiated in 1995.

There were several demonstrator projects supporting concept development. The SAT/Mark program, for evaluation of low observable technologies and development of standards, was launched in 1996 and was terminated in 2002. There was also a project called High Survivability Testbed evaluating technologies for ballistic protection. In total eight technology demonstrators were built.

The concept idea was to improve cost-effectiveness and performance using new technology. The solution sought was a modular multirole armored platform with: electric transmission, rubber tracks, decoupled running gear, a composite fiber hull, add-on ballistic protection and multispectral signature adaptation.

International cooperation was sought as part of the procurement strategy, e.g. within the West European Armament Group and other Scandinavian countries. There were serious discussions with the UK until 2007.

In 2006 BAE Systems Hägglunds $\mathrm{AB}$ was awarded the contract for initial development of SEP. See Fig. 1. The contractor was also to be responsible for the system design and integration. In 2008 FMV decided not to pursue further development because the government failed to find international partners.

Sources: Lindström [1], interview with Lindström ${ }^{2}$, and Olsson et al. [2].

\section{B. The Smyge and Visby class corvette programs}

In 1988 SwAF initiated the first conceptual study for the next class of surface ships. It resulted in concepts for three types of ships.

Already in 1987 a R\&D program for evaluation of low observable technologies, surface-effect-ship technology and integration of weapons in stealth vessels was initiated. The Smyge test vessel was launched in 1991 in order to support sea trials. The program ended in 1994.

The Visby concept idea was to exploit new technology in order to "combine the survivability, flexibility and endurance of a frigate, all in the economy of a corvette sized ship" [18]. The solution sought was a multirole surface vessel with limited crew size, made possible by automated defense systems, and survivability made possible by stealth and countermeasures.

International cooperation was sought and Singapore was involved in the program during the latter part of the concept stage.

\footnotetext{
2 Rickard O. Lindström, strategic specialist in combat vehicles at FMV, interview, 25th of March 2015
} 


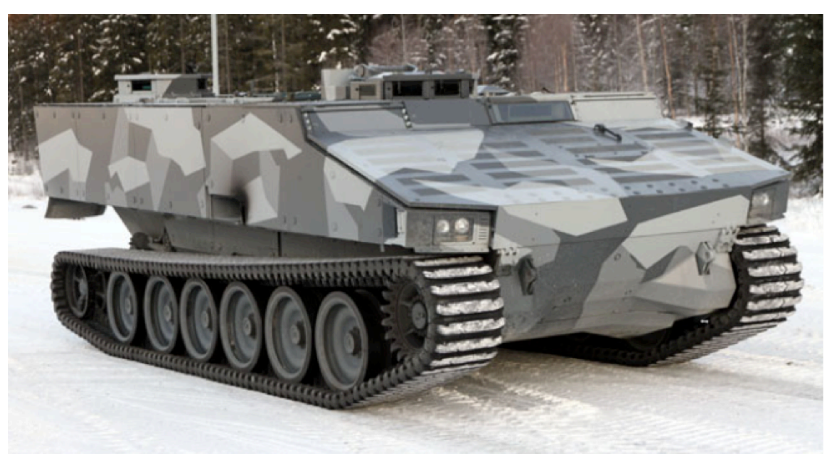

Figure 1. One of four pre-series SEP vehicles produced by BAE Systems Hägglunds AB in 2009. Photo courtesy of Rickard O. Lindström

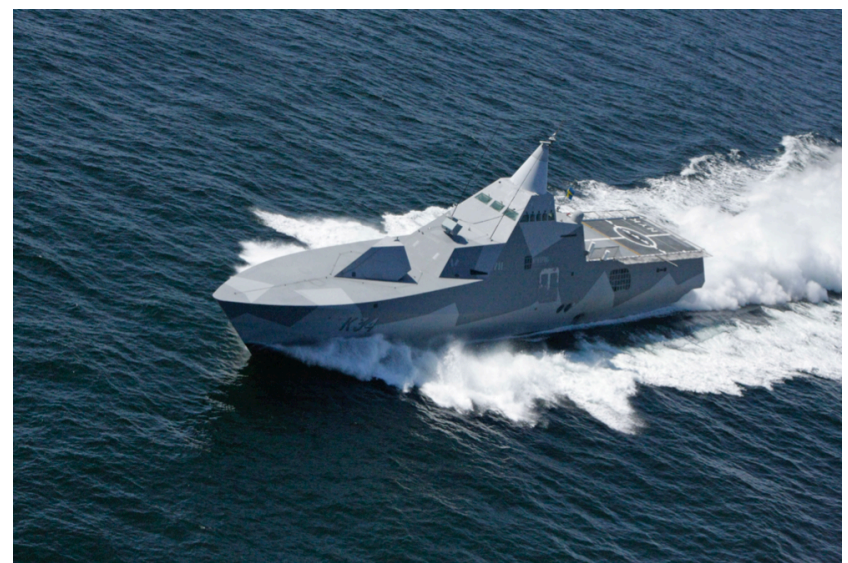

Figure 2. A Visby class corvette at high speed at sea in 2013. Photo Jimmie Andersson, Swedish Armed Forces

In 1995 FMV launched the Visby class development project. Kockums AB was awarded the contract to build the ship but FMV was to be responsible for system design and integration.

In 2009 the first two ships entered service. See Fig. 2.

Sources: Bergman [18] and interview with Mathiasson ${ }^{3}$.

\section{ANALYSIS}

Each subsection presents lessons identified consistent with the corresponding title SE-concept.

\section{A. Ensure coherent and traceable flow down of requirements (A1)}

In both cases the government established an integrated product team (IPT) approach early on. It enabled representatives of the design organizations to participate in requirements analysis activities at a military mission system level as early as the concept stage, thereby gaining a good understanding of stakeholder needs.

Requirements analysis started with identifying the dimensioning stakeholder requirements from relevant mission

${ }^{3}$ Urban Mathiasson, Cdr and naval engineer SwAF, interview, 12th of January 2016 scenarios. In both cases it was found necessary to first identify signature critical situations. In the SEP case the advance to contact was found the most important situation and in the Visby case it was the duel with anti-ship missiles.

Assessing the probability of various sensor threats occurring in the scenarios was found to be of central importance because this ultimately guides the prioritization of any conflicting needs to be satisfied by the design [2]. In the SEP case, situations with common sensor threats, such as eyesight or infrared sights, were given more weight than situations involving the presumed presence of sophisticated field radar sensors. In the Visby case the discussion about the occurrence of sensors was more binary; either there was a sensor threat or there was not. The probability assessment was found particularly challenging given the multirole concept, because in each mission type scenario there is a new main sensor threat. This places conflicting demands on the design.

Continued analysis then required the identification of the key measures of performance most relevant for desired capabilities. This link assures traceability between the system requirements derived and the stakeholder needs. The choice of key measures of performance at a tactical level, such as detection range, time to detection, or time to classification, was found to be heavily dependent on context. Hence, these measures can only be selected after an analysis of the specific operational context of interest.

The SAT/Mark demonstrator project found that coherence between stated platform requirements and tactical needs on the battlefield requires expressing system requirements as signatures, where signature is defined as "any property, or combination of properties, of an object, that makes it distinguishable from its immediate background by a sensor" [12]. However, the statistical nature of the background involved in signature measures presents challenges, particularly in the infrared signature domain, as reported in both cases. For example, the thermal contrast to background changes quickly if the platform is first heated by sun and then cooled by rain, or if the platform operates close to wooded terrain or in open spaces. The derivation of verifiable system requirements was made possible by selecting and specifying configurations with sets of situational parameters, including: sensor threat type, sensor elevations, target vehicle aspects, and typical backgrounds.

There were difficulties reported expressing all system requirements in a system signature format, especially for the radar and infrared sensor domains. In the Visby case the radar signature was for example measured in terms of the radar cross section of the ship in free space, which was advantageous for simulation purposes, but impossible to verify through measurements. There are also many different contrast measures possible. In the SEP case it was suggested that requirements should be categorized into three dimensions: spatial, spectral and temporal, for both active and passive sensors, thereby making it possible to state consistent signature system requirements regardless of sensor type. However, some of the resulting matrix elements lack relevant candidate measures. In summary, the difficulties identified make coherent flow down from stakeholder requirements, on the military mission level, to system signature requirements a challenge. 
At the system level, signature requirements had to be formulated as design instructions when allocating them to design at sub-system level, since signature requirements at the sub-system level was found not to make sense. Instead, the design instructions were iterated and reiterated until the system design fulfilled system requirements. Being able to model a system and to calculate its signature, e.g. the radar signature of the Visby hull, reduced uncertainty and hence the cost of iterations needed.

Furthermore, it is worth noting that the demonstrator projects played a major role in building the bank of knowledge necessary in the respective design organizations. In addition to the de-risking of technology and production methods, the demonstrator projects were crucial in forming viable design instructions and validating modeling tools.

\section{B. Share knowledge between government and contractor (A2)}

Until termination of the SEP program in 2008, both development programs, including the demonstrator projects, were implemented in accordance with a national procurement strategy that, at the time, had been in place for decades. It allowed the Swedish defense industry to benefit from development sponsored through government acquisition programs, thereby acquiring the use of expertise in export programs. In return, this expertise could be called upon in the next government acquisition program.

The respondents stated that the national procurement strategy at the time led to close collaboration between the contractors and the government agencies.

The involvement of contractors in the early phases through the integrated product team approach mentioned earlier promoted fruitful two-way communication. The contractor learned to better understand the needs and the procurer learned to better understand which requirements increased cost and complexity, and hence project risks.

In the SEP case risk eliminating studies, of such things as signature requirements, were performed continuously at the contractor. The consequences of system requirements, e.g. secondary impacts on other capabilities, were reported to the procurement agency. Key requirements were allowed to have the impact reported, whilst others were modified.

\section{$C$. Integrate the needs of the user organization (A3)}

The military user organization provided scenarios for the stakeholder requirements analysis in both cases. Ideally these should comprise: descriptions of anticipated missions, own tactics and procedures, anticipated physical environments and anticipated adversaries.

Developing the documentation of input mission scenarios into concepts of operation, as prescribed in best practice SE, would arguably be valuable. In the cases studied a lack of documented context seems to have been compensated for, to a large extent, by the long-term collaboration in IPTs.

\section{Establish systems baseline architecture early (B1)}

In both cases establishing stealth as a high-level design goal from the inception of the development program was found to be critical. The arguments were that otherwise the end result will not be stealthy, and if considered at an early stage, the cost of stealth is significantly reduced. In the SEP case it enabled a stealthy design largely using traditional materials. In the Visby case stealth was put forward, along with counter measures, as the most cost-effective solution to the challenge of building a ship with acceptable survivability in future combat scenarios.

\section{E. Employ best judgment in the use of technology (B2)}

It seems that innovation in both programs benefitted from the close collaboration between agencies and contractors. The modular principle of the SEP is one example, and the carbon fiber reinforced plastic hull of the Visby class corvette is another.

\section{F. System design shall proceed in a logical and orderly manner (C1)}

Functional decomposition was aided by a de facto rule for prioritizing efforts in some signature domains over others. Versions of the rule emerged in both cases based on a principle of minimizing the risk of costly corrections later on. Hence, in the case of the SEP, the designer addressed the radar signature first, then the thermal infrared signature, and lastly the visible and near infrared. In the handbook on LOT this was called the "work from inside out design rule" [12]. In the Visby case both the radar and magnetic signatures seem to have had high priority.

The early adoption of stealth as a key architectural principle was recognized resulting in few trade-offs or penalties on other attributes. In the SEP case there was some radar signature trade-off for ease of production during architectural design, and a low signature design of hatch handles was traded for functionality. In the visible domain a signature reduction coating was traded for maintainability. In the Visby case some radar signature was traded for lower technological risks in own sensor capability.

\section{$G$. SE shall be recognized and supported within the program (I2)}

Signature management was an influential and integrated element of the systems engineering organization. A system approach was seen as a necessity. In the SEP case, the program manager himself represented the contractor's signature engineering perspective. He was a member of the team of program specialists in the field. In the Visby case the FMV project manager appointed a signature coordinator to work closely with him, and across subprojects in the organization.

\section{H. Summary}

The workflow illustrated in Fig. 3 emerges from the analysis, covering requirements management and design activities. 


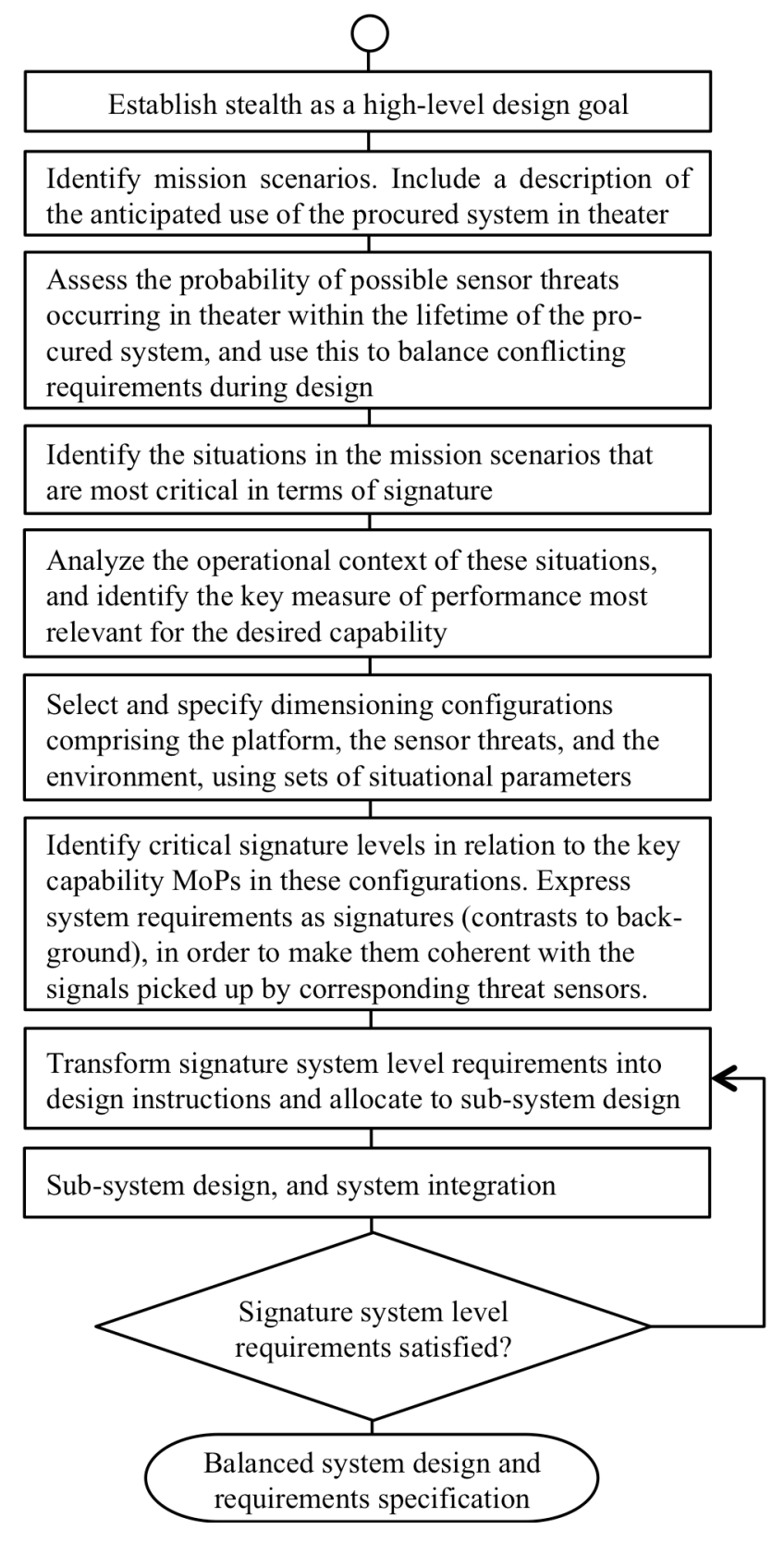

Figure 3. This is the workflow derived from the analysis of the SEP and Visby cases, covering requirements management and design activities.

The final result of the workflow illustrated is presumably a balanced, implementable, Low Observable design, typically documented in system or subsystem specifications.

The following major success factors can be identified:

- Establishing stealth as a high-level design goal at an early stage of system architecture design

- Executing a LOT demonstrator project during the concept life cycle stage reduce technology risks, supports identifying realizable signature levels, supports validating methods for modeling and measurements, and promotes mutual understanding between government agencies and design organizations.

- Establishing a process and organization for continuously monitoring system signatures during the design

- Working in integrated product teams facilitates: sharing of knowledge, sharing of high level measures of effectiveness, as well as a coherent flow down of requirements

In addition, the following major challenges were identified:

- Coherent flow down from military needs to lower levels is a major challenge due to difficulties expressing system requirements as signatures (contrasts to background).

- $\quad$ Stating verifiable signature requirements in the visible and infrared regions is inherently difficult due to the statistical nature of the background.

\section{DISCUSSION}

A preferred workflow for requirements management and design have been identified, and overall the results of the analysis is in reasonable agreement with the four success factors pointed out by the combat aircraft survivability community [section II]. (1) Survivability was seen an important part of system effectiveness; (3) survivability was a prioritized design goal established early on, and; (4) there was close cooperation between survivability engineers, designers and program management. Some question marks can, however, be raised regarding to what extent it was possible to analyze requirements on the SEP as a component in a mission system (2). In order to satisfactorily link military needs and system requirements it seems the following research questions need further attention:

- How should capability measures of effectiveness, such as detection range or time to classification, relate to a "cost effective weapon system" [Section II]. Arguably, with a mission system perspective, the design of a stealthy combat vehicle should be evaluated within the framework of a unit, e.g. a battalion conducting operations.

- How should signature measures of performance in the radar and infrared domains be expressed in order to be: coherent with relevant capability measures of performance, verifiable (measurable) and possible to model and simulate? Spatial, spectral and temporal contrasts all need to be included.

- And, how should the statistical variation in background be measured and expressed for the respective sensor domains?

The research approach used relies on both cases having succeeded in delivering properly balanced low observable designs, and there are good reasons to believe that they both did. Analysis of the case study results, using the FriedmanSage framework, suggests that both development programs adhered closely to good systems engineering practices. This is supported by a consensus among respondents and the end 
results in both cases seem to be well-balanced designs, which still satisfy signature requirements.

However, there is one major uncertainty in the method. It seems to the author, that the successful end results in the relatively immature domains of radar and infrared signature were not necessarily the result of well-justified, quantified, military needs. The analysis shows that it has been impossible to demonstrate a robust link between the military needs and stated system requirements. Instead, the seemingly successful end results were the result of a disciplined implementation of stealth architectural principles to obtain the best possible result in each domain. In both cases studied the program management strongly supported these principles, and, because there was no serious conflict between optimal stealth solutions and cost or other functional requirements during detailed design, stealth could be implemented with few trade-offs. This raises questions about whether or not the designs really represent the best achievable balance between stealth and other attributes.

Finally, the lessons were identified from studies of development programs governed by a Swedish national procurement strategy that is no longer valid. Hence, in order to generalize and to make recommendations for future development programs it is necessary to analyze the lessons identified in light of the European procurement environment of a near future. This analysis will be part of continued research.

Consequently, the workflow described for requirements analysis and design of Low Observable combat vehicles, with identified success factors, forms a good starting point for continued development and research.

\section{CONCLUSIONS}

The work reported is the first part of a research study with the aim to propose guidelines for the procurement of future Low Observable combat vehicles. The engineering processes of two Swedish development programs have been studied using a case study method - the SEP multirole armored vehicle and the Visby class corvette. The result is a thorough investigation of what worked in the cases studied. The following three conclusions are presented:

Firstly, a tentative workflow, tailored for requirements management and design in programs developing Low Observable vehicles, has been derived from lessons identified.

Secondly, apart from the tailored technical processes a shortlist of success factors has been derived. 1) the demonstrator projects (had multiple benefits), 2) the integrated product team approach established already in the study phase of the programs, and 3) establishing stealth as a key system design goal already from inception of the programs.

Thirdly, further research is needed to achieve coherence and traceability from military needs to requirements on lower system levels, including: expanding the system view to a mission system level, and defining measures of performance at all system levels.

\section{ACKNOWLEDGMENT}

This work was financially supported by the Swedish Defence University. The author would like to thank Martin Bang and Stephen Henly at the Swedish Defence University, Rickard O. Lindström and Anders Grop at the Swedish Defence Materiel Administration for valuable input, and of course the respondents for sharing their invaluable knowledge.

\section{REFERENCES}

[1] R. O. Lindström, “SEP: Multirole Armoured Platform”, Swedish Journal of Military Technology, 1999.

[2] Ö. Olsson, L. Karlsson, P. Lindwall, O. Dickman, and A. Grop, "A Systems Approach to Stealth on Ground; SAT/Mark Technology Demonstrator", Proc. SPIE, vol. 4718, 2002, pp. 1-11.

[3] J. Westin, Ö. Olsson, L. Pettersson, P. Lindwall, A. Grop, “Active control of infrared signature: system implementation in a ground vehicle”, Proc. SPIE, vol. 5075, 2003, pp. 39-48.

[4] G. L. Guzie, "Integrated Survivability Assessment", ARL-TR-3186, US Army Research Laboratory, White Sands, 2004.

[5] W. J. Goh, "Survivability design of ground systems for area defense operation in an urban scenario", Naval Post graduate School, CA, 2014.

[6] M. Burgess and G. Svetoslav, "Survivability for Deployable Protected Land Vehicles: Concepts, Models and Applications", J. Battlef. Technol., vol. 18, no. 2, 2015, pp. 7-13.

[7] D. Walden and G. Roedler, Eds., INCOSE Systems Engineering Handbook: A Guide for System Life Cycle Processes and Activities, 4th ed., John Wiley \& Sons, Hoboken, NJ, 2015.

[8] R. E. Ball, The Fundamentals of Aircraft Combat Survivability Analysis and Design, 2nd ed., Reston, VA: AIAA Education, 2003.

[9] R. K. Yin, Case Study Research - Design and Methods, 4th ed., Sage Publications Inc., Thousand Oaks, CA, 2009.

[10] Swedish Defence Research Agency, FOI, "SAT/mark (HKC) Slutrapport studiegrupp Krav", FOA-R--98-00874-615, 1998.

[11] Swedish Defence Research Agency, FOI, "SAT/Mark (MOC) Slutrapport SG modellering”, FOA-R--98-00883-615, 1998.

[12] L. Bohman, Handbook on Low observable technology for ground (swedish), FOI, Linköping, 2003.

[13] R. O. Lindström, L. Nilsson, K. Tapper, "Slutapport MS 136 SEP", FMV 34719/2009, 2009.

[14] RSSNS, Navy 2000 Symposium on the Visby class corvette, Royal Swedish Society of Naval Sciences, Stockholm, 2000.

[15] G. Friedman and A. Sage, "Case studies of systems engineering and management in systems acquisition", Systems Engineering, vol. 7(1), 2004, pp. 84-97.

[16] P. J. O’Brien, J. M. Griffin, "Global Positioning System Systems Engineering Case Study", US Air Force Center for Systems Engineering, Hobson Way, Ohio, 2007.

[17] B. Kinzig, "Global Hawk Systems Engineering Case Study", US Air Force Center for Systems Engineering, Hobson Way, Ohio, 2010.

[18] M. Bergman, "The development, in: Navy 2000 Symposium on the Visby class corvette", Royal Swedish Society of Naval Sciences, Stockholm, 2000. 